\title{
HAITÍ Y LA REPÚBLICA DOMINICANA FORMAN PARTE DE ESTA AMÉRICA NUESTRA
}

\section{HAITI AND THE DOMINICAN REPUBLIC ARE PART OF THIS AMERICA OF OURS}

Enrique Martínez: Centro de Iniciativas de Cooperación al Desarrollo. Universidad de Alcalá de Henares. Madrid (España)

enrique.martinez@uah.es

\section{CURRICULUM VITAE}

Secretario General del Centro de Iniciativas de Cooperación al Desarrollo (CICODE) de la Universidad de Alcalá de Henares (España). Autor de varios artículos científicos en libros y revistas universitarias.

\section{RESUMEN}

Haití es uno de los países más pobres del mundo y el más pobre del subcontinente. Urge, por tanto, una acción coordinada de la comunidad internacional que debe dejar a un lado sus divisiones coyunturales. El Gobierno de la República Dominicana debe tomar conciencia de la necesidad de facilitar cuantas medidas preventivas sean necesarias para aliviar una situación como la que se avecina en su país vecino, Haití. 


\title{
PALABRAS CLAVE
}

Haití - República Dominicana - Pobreza - Comunidad Internacional

\begin{abstract}
Haiti is one of the world's poorest countries and poorest continent. Urges, therefore, a coordinated action by the international community must put aside their divisions circumstantial. The Government of the Dominican Republic should be aware of the need to supply all necessary preventive measures to alleviate a situation like that is coming in its neighbor, Haiti.
\end{abstract}

\section{KEY WORDS}

Haiti - Dominican Republic - Poorness - International Community

\section{TEXTO:}

No es necesario recordar las cifras, tan manidas, en relación con Haití, que siempre manejamos quienes estamos trabajando con América. Ya todos saben, o deben saber que Haití es uno de los países más pobres del mundo y el más pobre -triste título- del subcontinente. Para qué recordar índices y estadísticas si basta con abrir los ojos a una realidad lacerante desde cualquier punto de vista, en particular la situación de los más desprotegidos: los niños, las mujeres, los enfermos, los marginados -es decircasi todos los haitianos. 
Resulta poco útil ahora hacer mención a la miserable herencia dejada por la civilización europea en la primera de las repúblicas americanas que se declaró independiente. Es mucho más importante rescatar de las hemerotecas y de los archivos de los organismos internacionales los testimonios de aquellos que luchan diariamente por aliviar al pueblo haitiano de su sufrimiento. Testimonios en su mayoría desoídos por la comunidad internacional, más preocupada muchas veces por la orientación del voto de Haití en la Asamblea General de Naciones Unidas o por cómo instrumentalizar su presencia en organizaciones internacionales, que por atender a la situación en que malviven los siete millones de habitantes de la parte occidental de la isla caribeña.

Tras el ominoso período vivido por Haití bajo la sangrienta y feroz dictadura personal de los Duvalier y la junta militar que fue su secuela, la llegada al poder en febrero de 1991 del sacerdote católico Jean-Bertrand Aristide abrió nuevas perspectivas para el país. Un golpe militar frustró ese primer intento de regeneración política y económica. Su regreso, en 1994, fruto de las presiones internacionales dio paso a las elecciones de diciembre de 1995 que alzaron a la presidencia a René Préval. El período convulso vivido por el país entre esa fecha y la nueva elección como presidente de Aristide, en diciembre de 2000, contribuyó a sumir al pueblo en una situación de penuria equiparable a la del régimen de los Duvalier.

Las fuerzas de oposición al gobierno de Aristide están a punto de lograr hacerse con el poder. Mientras tanto, Haití sigue sumido en la más absoluta incuria, agravada por la lucha armada. En medio de este caos, centenares de miles de hombres y mujeres haitianos sufren las consecuencias de un abandono histórico por parte de sus gobernantes y de la comunidad internacional. Las lacras del analfabetismo, de las epidemias (en particular el SIDA), del hambre y de la carestía, arrasan a un pueblo hundido en la más absoluta desesperanza y moralmente desarmado. Los derechos 
humanos no tienen hoy reconocimiento efectivo en Haití y el mundo no puede permanecer al margen de ese hecho.

Pero lo peor, aunque parezca que nada más puede lastrar el sufrimiento del pueblo haitiano, esta aún por venir. Si nada lo impide, en días, quizá en horas, mareas humanas de haitianos trataran de huir del país, inevitablemente con rumbo a la frontera dominicana. Único país vecino, la República Dominicana, con el que viene manteniendo desde hace muchos años una relación tensa tendrá que hacer frente a la situación. Millares de eres humanos huirán hacia esa frontera yerma donde la pobreza y la marginación azotan por igual a haitianos y dominicanos. ¿Quién va a ocuparse de ellos, si no tienen otra cosa que compartir mas que su abandono?

Urge, por tanto, una acción coordinada de la comunidad internacional que debe dejar a un lado sus divisiones coyunturales y sus argumentos a favor de la "no injerencia en los asuntos internos". Una doctrina sin duda muy apropiada para otros momentos y otras situaciones, pero no para la situación que hoy vive Haití y que -de no remediarlo pronto- pueden vivir los dominicanos que habitan en las zonas limítrofes. Conviene asimismo que el gobierno de la República Dominicana tome conciencia de la necesidad de facilitar cuantas medidas preventivas sean necesarias para aliviar una situación como la que se avecina. Es responsabilidad ésta que ningún gobierno democrático puede, en conciencia, eludir. El noble pueblo dominicano, que en otro tiempo también ha sufrido los rigores de la guerra, la ocupación extranjera y la dictadura, debe tender una mano generosa -con ayuda de las naciones caribeñas y el apoyo de los países desarrollados- a sus vecinos haitianos que pasan por tan graves momentos.

Pido a nuestros lectores habituales y a quienes desean sinceramente la paz, el progreso y la libertad para los pueblos de esta América nuestra que allá donde se encuentren hagan cuanto esté en sus manos por manifestar su apoyo y su solidaridad 
en este trance a los hombres y mujeres de Haití y a los de nuestra querida nación hermana, la República Dominicana. 